\title{
QUEM É DA FAMÍLIA? REFLEXÕES SOBRE PARENTESCO E MOBILIDADE
}

\author{
Who's in the family? Reflections on kinship and mobility
}

\author{
lana dos Santos Vasconcelos ${ }^{1}$ \\ Sandro Martins Almeida Santos ${ }^{2}$
}

\begin{abstract}
Resumo. O artigo apresenta comparação entre dois processos migratórios distintos, com base nas relações de parentesco e nas metáforas sobre família. A pergunta, "quem é da família?", é respondida em diálogo com os novos estudos de parentesco na Antropologia e, sobretudo, enfocando as concepções e obrigações de família presentes entre viajantes alternativos radicados no interior de Goiás e entre trabalhadores brasileiros nos garimpos na Venezuela. Pode-se dizer que pessoas se colocam em movimento atendendo alguma transformação ou necessidade de transformação. Alternativos sonham com um novo estilo de vida e os garimpeiros com trabalho e riqueza. Nos casos em tela, as famílias, cada uma a seu modo, assumem centralidade, uma vez que são percebidas enquanto causa e efeito da condição de mobilidade.
\end{abstract}

Palavras-chave: parentesco, mobilidade, trabalho, estilo de vida.

\begin{abstract}
The paper presents comparison between two distinct migratory processes, based on kinship relationships and family metaphors. The question, "who's in the family?" is answered in dialogue with the new kinship studies in Anthropology and, mainly, focusing on family conceptions and obligations between alternative travelers living in Goiás' countryside and between Brazilian workers at the mining camps in Venezuela. It can be said that people set themselves in motion in response to some transformation or need for transformation. Alternatives dream of a new lifestyle and the miners with work and wealth. In the cases on screen, families, each one in its own way, assume centrality, since they are perceived as cause and effect of the mobility condition.
\end{abstract}

Keywords: kinship, mobility, work, lifestyle.

1 Programa de Pós-Graduação em Antropologia Social da Universidade Federal de São Carlos (UFSCar). Bolsista FAPESP processo n. 2016/14055-0. Boa Vista, RR, Brasil.

2 Programa de Pós-Graduação em Sociedade e Fronteiras (PPGSOF), na Universidade Federal de Roraima (UFRR). Boa Vista, RR, Brasil. 


\section{Introdução}

O presente exercício analítico traz como referencial etnográfico e teórico o cruzamento de duas experiências de pesquisa envolvendo distintos fenômenos migratórios em contexto transnacional ${ }^{3}$. As famílias, nestes cenários, tornam-se projetos constantemente construídos e reavaliados, atualizando práticas diferentes de proximidade e distância entre "pessoas consideradas da família". O primeiro referencial apresenta a concepção de "família" e as relações de parentesco desenvolvidas entre viajantes de várias nacionalidades radicados(as) em Alto Paraíso de Goiás, interior do Brasil. O segundo, as relações familiares transnacionais estabelecidas por brasileiros(as) que trabalham na fronteira entre Brasil e Venezuela, especialmente nas localidades de garimpos. Pode-se dizer que pessoas se colocam em movimento atendendo alguma transformação ou necessidade de transformação. Alguns buscam ouro, trabalho, sobrevivência nos garimpos da Venezuela, enquanto que outros procuram bem-estar espiritual, afirmação de um estilo de vida "alternativo" e afetividade em cidades do interior do Brasil.

Foi preciso encontrar um princípio de simetria para comparar e compreender as diferentes condições de vida migrante. Temos uma busca de melhoria das condições de vida material (no caso do garimpo/ trabalho transfronteiriço) e também uma busca de melhoria das condições de vida espiritual (no caso dos alternativos). A chave para encontrar uma equivocação entre os dois contextos e que norteará o artigo é a experiência de "família" que, apesar das discrepâncias, se mostra esclarecedora de determinadas recorrências no tocante às migrações humanas, como a circulação de coisas e trabalho, importantes na manutenção e na criação de "relacionalidades", expressas em vínculos duradouros de lealdade e afetividade ${ }^{4}$.

O material de campo analisado é oriundo de uma tese de doutorado ${ }^{5} \mathrm{e}$ de uma dissertação de mestrado ${ }^{6}$, defendidas em 2013. Apesar das pesquisas abordarem realidades discrepantes como as "comunidades alternativas" e os "garimpos", a revisão dos dados coloca em evidência uma fértil analogia entre as duas etnografias. As "famílias", com suas diferenças, existem enquanto causa e efeito da mobilidade. Enfatizamos, por meio da comparação, que os deslocamentos de pessoas oportunizam transformações nas relações de parentesco, assim como as relações de parentesco condicionam os processos

\footnotetext{
3 Agradecemos o incentivo e as críticas de Anna Catarina Morawska Vianna, professora do PPGAS/ UFSCar, na realização desta "experimentação etnográfica".

4 CARSTEN, Janet. Cultures of Relatedness: new approaches to the study of kinship.

5 SANTOS, Sandro. A família transnacional da Nova Era e a globalização do (((amor))) em Alto Paraíso de Goiás, Brasil.

6 VASCONCELOS, lana. Articulações familiares transnacionais: estratégias de cuidado e manutenção familiar na fronteira Brasil/Venezuela.
} 
migratórios, influenciando seus caminhos e a circulação de pessoas, coisas e informações.

Alto Paraíso é cenário, desde os anos 1980, para experiências de comunidades alternativas envolvendo brasileiros e estrangeiros ${ }^{7}$. As comunidades variam em grau de abertura e trocas com o mundo industrial - existem aquelas que almejam alcançar uma autossuficiência produtiva e outras que funcionam como retiros espirituais de luxo e sobrevivem de suas relações com as cidades. A duração das experiências mais radicais, via de regra, foi breve. Entre idas e vindas, aquelas pessoas que decidiram fixar residência em Alto Paraíso, nas zonas urbana e rural, afirmam que a comunidade alternativa existe distribuída pela cidade e arredores. Remanescentes dos diferentes movimentos entendem que essa comunidade dispersa agora é a sua família.

Já o fluxo migratório internacional na Fronteira Brasil/Venezuela está associado aos períodos de declínio da garimpagem na Amazônia e, especificamente, em Roraima, a partir da década 1970, com o declínio da mineração na região do Tepequém e na região nordeste do estado. Esse segundo movimento migratório foi marcado pela proibição da atividade de garimpagem no Brasil na década de 1990, atraindo muitos trabalhadores brasileiros para Venezuela, onde a atividade era legal. Os brasileiros foram especialmente para o estado Bolívar, fronteira com o estado brasileiro de Roraima. Portanto, os dados apresentados são de migrantes brasileiros(as) habitantes em localidades venezuelanas vizinhas a Santa Elena, situadas em regiões de garimpo, tais como Las Claritas, "km 88" e El Pauji (Icabarú). As "famílias" vivem neste cenário uma complexa articulação de relações sociais que as põem em contato constante com imagens e práticas que categorizam os integrantes da família de acordo com a sua adesão formal, ou mesmo informal, a entidades nacionais diferentes. Em outras palavras, a relação com as famílias se passa à distância e é mediada pelas fronteiras nacionais ${ }^{8}$.

Discutiremos a relação entre as duas experiências de "família" à luz das ferramentas analíticas dos novos estudos de parentesco no campo da Antropologia, os quais procuram abordar as relações familiares a partir dos

\footnotetext{
Alto Paraíso de Goiás (6.885 hab., Censo 2010) localiza-se a $200 \mathrm{~km}$ ao norte de Brasília. É destino turístico pelas cachoeiras e biodiversidade do Parque Nacional da Chapada dos Veadeiros. Além disso, a cidade é a "terra prometida" para inúmeros projetos engajados com o despertar para uma Nova Era. Transitavam pela cidade, em 2011, 260 indivíduos com quem o pesquisador conviveu, sendo eles 140 brasileiros e 120 estrangeiros de trinta e sete bandeiras diferentes, com idades que vão dos 17 aos 70 .

8 As interpretações e informações são provenientes da pesquisa durante seis meses em 2013 na cidade de Santa Elena de Uairén e também de dados coletados durante período de 09 a 16 de abril de 2011 no âmbito do projeto de pesquisa Migração e Relações de Trabalho na Fronteira Pan-Amazônica, financiado pelo CNPq/Edital CHS 2009-2011 coordenado pela profa Francilene Rodrigues nas localidades de garimpos Las Claritas, Km 88 e Icabarú, ocasião em que foram aplicados 80 questionários a 53 homens e 27 mulheres.
} 
conceitos e formas de relação próprios ao grupo estudado, evitando, assim, incorrer na imposição do modelo da sociedade do pesquisador sobre os modelos dos indivíduos estudados ${ }^{9}$. A mobilidade pode ser entendida como fator que influencia na fabricação dos novos vínculos afetivos mediados por convenções dos lugares de origem e reorganizadas nos lugares de trânsito/ residência. As associações aqui apresentadas serão limitadas pelas relações que os interlocutores descreveram em campo. A analogia, neste sentido, se dará por conta do contexto, concebido não como algo que determina, mas que traz pistas para refletirmos sobre as realidades estudadas ${ }^{10}$.

A experimentação proposta para o texto é justamente encontrar os pontos de encontro e desencontro entre as duas realidades, partindo de uma "obviação" das noções de família presentes em ambas. Considerando as diferentes formas pelas quais se manifestam as construções sociais chamadas de família, pretende-se conhecer as associações produzidas pelas pessoas visando dar sentido às conexões entre elas. O intuito seria revelar as relações entre os dois contextos, a partir de suas diferenças e não somente com base em uma suposta semelhança manifesta pela presença comum de uma ideia de família.

As famílias de alternativos e garimpeiros ${ }^{11}$ caminham muitas vezes em direções contraditórias. Por um lado, em Alto Paraíso se observa a extensão da casa, da família, da própria noção de humanidade, estimulando a abertura para incorporação de novos parentes tendo em vista o compartilhamento de uma filiação mítica com a Mãe Natureza; por outro, nos garimpos, o relacionamento com a família distante destaca-se como meio de afirmação da condição de gente, separada dos animais, com ênfase na continuidade das relações biogenéticas da filiação e da aliança para reprodução. O que a comparação nos revela é que a metáfora da família é, ao mesmo tempo, causa e efeito da criação de obrigações entre as pessoas, seja qual for a ênfase dada para explicar as relações de parentesco. Percebe-se, na esteira de Marcel Mauss ${ }^{12}$, que a circulação de dons (dar, receber e retribuir) fortalece as obrigações entre as pessoas, destacando-se como um elemento importante na produção das famílias, a despeito da distância entre seus membros ou a despeito das diferenças de origem entre eles.

O presente artigo está estruturado em quatro sessões. No primeiro momento, apresentaremos as duas distintas concepções sobre o que é família. $\mathrm{Na}$ segunda sessão, relacionamos os constructos analíticos sobre parentesco

9 CARSTEN, op. cit.

10 STRATHERN, Marilyn. Kinship at the core: an anthropology of Elmdon.

${ }^{11}$ Nesta pesquisa, garimpeiro ou "minero", como são chamados na Venezuela, são aqueles que se reconhecem como tal e que, direta ou indiretamente, estão ou estiveram envolvidos na atividade de mineração e que associam essa atividade com seu modo ou estilo de vida.

12 MAUSS, Marcel. Ensaio sobre a Dádiva. 
na Antropologia com os materiais etnográficos abordados. Num terceiro momento, somos impelidos ao debate sobre as dádivas em ambos os contextos de transnacionalidade. À guisa de considerações finais, por meio da "obviação" entre as noções de família de garimpeiros e alternativos, buscaremos os contrastes que revelam os limites e potenciais das nossa proposta analítica. Trata-se de uma experiência que pode ser replicada para contribuir no estudo de outras redes migratórias.

\section{Construtos locais de família: la mineria e a comunidade alternativa}

Na perspectiva de perceber as formas que são comuns entre os diferentes contextos e em que medida podem ser contrastadas, procuramos compreender como as transformações que caracterizam os processos migratórios analisados - de um lado, as oportunidades de trabalho, e de outro, a mudança de estilo de vida - concorrem na diferenciação entre quem faz e quem não faz parte da "família".

Os dados das pesquisas oferecem pistas para compreensão das formas de família em contextos de mobilidade. Para os alternativos de Alto Paraíso, as relações de familiaridade são nutridas por relações de reciprocidade que estabelecem a continuidade das relações afetivas e de lealdade apesar das diferenças de origem - não há ênfase sobre as relações consanguíneas. Na falta de reciprocidade, ocorre um distanciamento das relações e isto pode acontecer entre parentes consanguíneos e/ou afetivos, geograficamente perto ou longe $\mathrm{e}^{13}$. Já para os migrantes brasileiros nos garimpos da Venezuela, o que ganha centralidade é a circulação de coisas, presentes e uma memória positiva a respeito da manutenção de vínculos de consanguinidade. Quando não é possível manter o envio de presentes/coisas, o contato com a família consanguínea é perdido totalmente, mas o pertencimento à família é reafirmado por meio das lembranças descritas pelos(as) migrantes, mesmo quando o contato com os parentes já foi interrompido há mais de dez anos.

A família consanguínea assume conotações diferentes entre esses grupos pesquisados. De um lado, para os(as) brasileiros(as) no garimpo da Venezuela, significa a condição de estabelecido em um lugar e a recusa da condição de outsider no contexto de mobilidade. Do outro, para os alternativos, a vinculação à família consanguínea, pelo contrário, é um fator de imobilização, à medida que reforça valores e práticas de estruturas sociais das quais se deseja afastar. Indivíduos contraculturais exercitam uma conduta desviante daquela das instituições do local de origem, tais como a família patriarcal, os Estados, Igrejas e Corporações ${ }^{14}$.

${ }_{13}$ LOBO, Andrea. Tão Longe, Tão Perto: famílias e 'movimentos' na Ilha da Boa Vista de Cabo Verde.

${ }^{14}$ VELHO, Gilberto. O estudo do comportamento desviante: a contribuição da antropologia social, p. 60. 
De acordo com as concepções de família abordadas aqui, temos, na visão dos místicos/alternativos, uma busca para encontrar uma família planetária, superando as fronteiras da nacionalidade por meio da construção de um emaranhado social que atravessa as "comunidades imaginadas" nacionais. Os alternativos defendem um senso de cosmopolitismo (algo inspirado no cosmopolitismo liberal kantiano) segundo o qual todos os seres nascidos no planeta Terra são filhos de uma mesma mãe Natureza e possuem, por isso, um parentesco comum extensível por toda a superfície terrestre. No plano mítico, pós-incestuoso ${ }^{15}$, todos(as) são potencialmente irmãos(as) e potencialmente esposos(as). Assim expressou-se um argentino que mora há mais de dez anos no interior do Brasil:

Para mi, globalização é a comunicação e o transporte que permitem uma sociedade planetária. Isto já está ai. La gente precisa aceitar este fato e se abrir para conhecer todas as diferentes influências. [...] Esse negócio de separação e identidade só é divertido na época da Copa do Mundo (risos)! ${ }^{16}$

Para o caso dos(as) migrantes brasileiros(as) nos garimpos venezuelanos a circulação de coisas e pessoas é algo dado pela dinâmica do espaço. A "nacionalidade" passa a ser concebida no espaço fronteiriço muito mais pelas lógicas regidas pelas interações sociais com os agentes governamentais do que pelos instrumentos oficiais regulatórios dos dois países. Assim, a suposta cidadania aqui é idealizada pela convivência entre os diferentes grupos nacionais:

Minha mulher tinha ficado trabalhando no restaurante em Boa Vista, enquanto eu organizava o local do restaurante aqui em Santa Elena. Quando estava tudo pronto mandei o recado para mulher vender tudo que tinha lá e vir embora para cá com prato, louça, talher para gente trabalhar no restaurante aqui. A mulher vendeu e veio embora com meus dois filhos. Quando minha mulher veio que passou na polícia federal com as coisas os policiais ficaram assim... ai ela falou sou esposa do José Laércio Borges, ninguém sabia quem era, mas um amigo também parou e falou: essa é a mulher do Zebrinha, os federais responderam: Ah, mulher do Zebrinha, então pode passar. (homem, natural do Amazonas, 81 anos, 38 anos em Santa Élena do Uairén) ${ }^{17}$.

Obstante ao contexto de Alto Paraíso, categorias como identidade e globalização não são acionadas nos discursos dos(as) garimpeiros(as). Estes acionam categorias nativas como, por exemplo, o termo paisano, utilizado para referir-se a outro(a) migrante brasileiro(a) - indicando a mesma nacionalidade.

\footnotetext{
${ }^{15}$ VIVEIROS DE CASTRO, Eduardo. Metafísicas canibais: elementos para uma antropologia pósestrutural, p. 150-151.

16 SANTOS, op. cit., p. 42.

17 VASCONCELOS, op. cit., p. 88.
} 
Outras categorias nativas bastante ilustrativas do processo de produção de diferenças do contexto familiar garimpeiro na Venezuela são as denominações Mira e Garimpeiro. A denominação Mira é oriunda da apropriação da expressão do idioma espanhol, constantemente utilizada em situações que é necessário chamar atenção e/ou se referir a algo. Nas relações familiares, representa uma categoria de transformação, mostra índices de "venezuelização" atribuídos pelos brasileiros(as) que passam a incorporar práticas culturais venezuelanas no seio da família, sendo percebidos gradualmente como nacionais na Venezuela. Por outro lado, aqueles que se deslocam na fronteira para atuarem em atividades informais e que não possuem vinculo familiar, são denominados(as) garimpeiros. Esse grupo de migrantes brasileiros(as) é visto pelos nacionais venezuelanos como pessoas de fora, ou fora da lei ou fora da moralidade e, consequentemente fora de qualquer família (seja na Venezuela ou mesmo no Brasil). Neste contexto "ser ou não ser da e de família" assume centralidade, à medida que migrantes brasileiros(as) membros de famílias compostas por pessoas de nacionalidade venezuelana colaboram para construção de uma relação de pertencimento com a Venezuela e aceitação pelos nacionais (Mira).

O ponto paradoxal entre as noções de família acionadas pelos garimpeiros brasileiros na Venezuela e pelos alternativos globais em Alto Paraíso diz respeito aos termos incorporados no discurso "nativo" que também estão presentes nos estudos migratórios. Por exemplo, conceitos como identidade, globalização, nacionalismo, são encontrados nos discursos alternativos, por outro lado, quase nunca são mencionados no discurso dos garimpeiros. Isso sugere a existência de distintos sistemas de conhecimento compartilhados por esses grupos. Por um lado, temos uma ideologia disseminada em todo mundo de uma "cultura de paz" que valoriza uma reaproximação com a natureza e a espiritualidade, derivada de um cosmopolitismo liberal. Por outro lado, temos uma busca pelo $E I$ Dourado, um mito compartilhado sobre um lugar de riquezas incalculáveis e de rápido enriquecimento econômico. Nos garimpos, está presente a esperança de, talvez um dia, bamburrar ${ }^{18}$; enquanto que no Alto Paraíso de Goiás, a esperança é pelo despertar de uma nova civilização de paz e amor.

\section{Aspectos da produção de vínculos familiares}

As razões para o estabelecimento de núcleos familiares em terras estrangeiras variam de família para família, ou, de forma ampla, de migração para migração. As possibilidades de entrar e sair, trabalhar, amar e morar são alguns fatores condicionantes na seleção das localidades. Migrantes, de maneira geral, situam-se em um contexto de vulnerabilidade que pode ser financeira, legal ou mesmo afetiva. A chegada como estrangeiro e a possibilidade de

\footnotetext{
18 Para os garimpeiros, bamburrar é tirar a sorte grande, acertar na procura de um diamante precioso, encontrar uma pesada pepita de ouro, alcançar o sucesso financeiro.
} 
permanência em um novo local são, em larga medida, influenciadas/limitadas pelas políticas nacionais/locais de imigração. As famílias e grupos de migrantes desenvolvem mecanismos para negociar sua permanência conforme o contexto. Cada localidade há de revelar peculiaridades na maneira como as malhas de uma comunidade transnacional são arranjadas no intuito de contornar as vulnerabilidades inerentes à mobilidade ${ }^{19}$.

Ambas as realidades etnográficas abordadas aqui reforçam a diversidade de configurações que um espaço transnacional pode assumir ${ }^{20}$, especialmente em virtude da mobilidade em sua conformação e, por conseguinte, nas diferentes concepções de família. No caso dos(as) alternativos(as) de Alto Paraíso, a negação de uma identidade nacional especifica e a afirmação de uma identidade planetária (aldeia global) é que cria uma noção de família vinculada a um imaginário compartilhado e um estilo de vida. Já no caso dos garimpeiros, é a afirmação de uma cidadania nacional que os vincula a uma família e sobretudo, a vinculação de laços consanguíneos no e/ou país de origem e destino que demonstram que são " pessoas de família".

A primeira casa construída na Fazenda Paraíso, lócus principal da pesquisa de Santos ${ }^{21}$, é descrita como um ambiente sem distinção formal entre dentro (privado) e fora (público). Construída com poucas paredes/portas, uma vez abertas, transformam em um único ambiente de movimento livre com vista para um lado e outro da casa. Mais do que aberta arquitetonicamente, a casa é uma experiência de hospitalidade tal qual sonhada pelo desobediente e místico Henry Thoreau²: "o hóspede já é parte implícita da família, ele ou ela é recebido como igual e não como um 'outro'".

O fluxo de viajantes na Fazenda é constante. A família dos alternativos tende à expansão com a chegada de novos viajantes. As casas, as fazendas, os projetos ecológicos, os projetos de comunidades alternativas são abertos para quem tem autoconfiança de chegar e contribuir com sua presença. Não seria a mesma coisa receber hóspedes apenas em troca de um aluguel determinado. O anfitrião, Lukas, por exemplo, não faz da casa, que demorou três anos para ser construída, uma pousada, mas ele sempre tem amigos chegando e partindo, além de grandes refeições coletivas. Ele gosta de ver o ambiente movimentado, com as pessoas exercendo sua criatividade enquanto ele também exerce a dele: prima-se pela cooperação ou, como dizem, cocriação de um ambiente favorável à preservação das individualidades. Evidentemente, como todo sistema em expansão, a família também é caracterizada pela dispersão e

\footnotetext{
${ }^{19}$ BRYCESON, Deborah, VUORELLA, Ulla. The transnational family: new European frontiers and global net workings.

20 RIBEIRO, Gustavo. A condição da transnacionalidade.

${ }^{21}$ Ibidem.

22 THOREAU, Henry David. Walden ou a vida nos bosques.
} 
fragmentação. A ênfase no individualismo provoca conflitos que são dissipados com a mudança de algum morador para outra fazenda ou casa na cidade.

Partindo de uma concepção de indivíduo cosmicamente (material e espiritualmente) conectado a todas as outras criaturas da Terra, o alemão Franz (54 anos), que é mecânico, inventor, e pessoa reconhecida localmente por sua veia filosófica, elaborou a sua teoria de parentesco:

A primeira coisa é que todo mundo tá com certeza que família é o que geneticamente está conectado. Mas todos nós estamos geneticamente conectados. E a descoberta minha sempre era que a verdadeira família é aquela que eu estou descobrindo ao longo da minha vida, que pode ser os pais, pode ser os irmãos ou os filhos, mas pode ser também que não. Então família aqui em Alto Paraíso parece encontro de pessoas de várias partes do mundo que se unem descobrindo que eles fazem parte de uma família, sentindo, então. Para mim família é sentir, sentir fazendo parte da família ${ }^{23}$.

Entendemos que uma chave para compreender o parentesco entre os moradores contraculturais de Alto Paraíso de Goiás, seja justamente a existência desse "descobrir-se sentindo parte de uma família", apontado por Franz. Um sentimento dinâmico, compartilhado, de mútuo pertencimento a uma mesma malha de relacionamentos afetivos. Note-se que não há uma substituição de "modelos" (contracultural em oposição ao biológico), porém uma extensão por meio de colaboração continuada e de uma filiação mítica à Mãe Natureza. Mas como as pessoas se descobrem parentes de fato?

Os amigos são recebidos como parentes e isso implica que eles são recebidos não como hóspedes, mas como indivíduos igualmente responsáveis pela vida em comum no espaço da casa e da fazenda. Nos primeiros dias, o morador mais antigo mostra todas as ferramentas e os recursos disponíveis que podem ser transformados. Com o passar dos dias e a ambientação do recémchegado, é comum que ele ou ela se envolva mais diretamente em várias das tarefas diárias de manutenção da vida na fazenda.

No período de apenas uma semana hospedado, o parente jordaniano Adnan (32 anos) encontrou bambus gigantes que estavam abandonados, fez Lukas mostrar onde estavam as lonas e ergueu, sozinho, uma tenda tipi (construção ameríndia comum na América do Norte). O alemão Sebastian (31 anos), em outra oportunidade, trocou a estadia de um mês na casa de Lukas por sessões de massagem. Sua companheira, a polonesa Olga (28 anos), fez massagens e ainda deixou os arredores da casa decorados com morangos plantados em jarros suspensos. O ítalo-brasileiro Rafael (26), por sua vez, chegou despretensiosamente, como mais um viajante em busca de

${ }^{23}$ SANTOS, op. cit., p. 270. 
experiências espirituais e amizade com pessoas que compartilham um estilo de vida alternativo. Rafael não foi mais embora (já está lá há mais de 6 anos e construiu uma casa na propriedade rural), diz ter encontrado sua família ali. Ele passa alguns meses por ano na Europa trabalhando para juntar dinheiro e investir em melhorias na casa e na fazenda.

De acordo com a croata Marija Ludovic, ex-companheira de Lukas e que vive atualmente em outra casa na mesma fazenda, a vantagem de uma família está no reconhecimento mútuo da importância da contribuição individual para a sobrevivência comum: "Sem família, vida fica mais difícil. É preciso saber valorizar trabalho que cada um faz. Não existe trabalho mais importante que outro. Cuidar todo dia da criança é tão importante como trazer comida para casa".

Já no contexto da mineria, a família é uma referência distante. Obedece outra lógica de pertencimento não atrelada à coabitação e/ou sua ampliação a outros membros, mas aos laços de filiação e matrimônios deixados no país de origem. Tendo em vista a escassez de vínculos de parentesco no garimpo, a lembrança da família no Brasil costuma ser a única referência de lar: "O lugar que considero como minha casa é lá em Manaus, porque minha filha tá lá, minha mãe tá lá (mulher, 48 anos, natural do Amazonas, 12 anos em Sta. Élena do Uairén)" 24.

A casa e/ou lar não se restringem ao espaço de convivência, mas ao sentimento de pertencimento à família, aos laços de consanguinidades estabelecidos em algum lugar. Quando questionados sobre o local onde moram é recorrente ouvir os garimpeiros se referirem à casa como o lugar onde conviveram a última vez com mães, irmãos(as), esposas e filhos(as), embora vivam há muito tempo na Venezuela e nunca mais tenham voltado para visitar os parentes no Brasil.

A família, diferentemente de Alto Paraíso, é reafirmada a todo momento por parâmetros de hierarquia, controle social e poder concentrado, em geral na figura masculina. Muitos dos garimpeiros ressaltam de forma orgulhosa o cumprimento da responsabilidade de provedor do lar distante, mesmo em momentos em que a extração do ouro é parca.

O garimpo, embora seja um ambiente considerado altamente masculinizado também é experienciado pelas mulheres que não atuam diretamente na atividade de mineração, mas compõem uma rede indireta de prestação de serviços, trabalhando como cozinheiras, lavadeiras, vendedoras ambulantes, entre outros. O ambiente precário dos acampamentos dos garimpos também proporciona espaços de moradias coletivas. Em geral, são barracas construídas com a madeira extraída da própria floresta e revestidas com lona preta. No caso dos garimpos, os locais sem paredes são os locais onde vive a "gente sem família". As barracas que possuem a estrutura de madeira

${ }^{24}$ VASCONCELOS, op. cit., p. 90. 
revestida de lona nas laterais são comumente habitadas por cônjuges e seus filhos(as) pequenos(as).

Também as mulheres estão empenhadas no envio de proventos às suas famílias distantes. As remessas são encaradas, cobradas e realizadas de diferentes maneiras entre homens e mulheres. Para as mulheres o envio de bens representa, além da ajuda financeira, uma forma de compensação pela transferência temporária dos trabalhos dos cuidados com os filhos para outras mulheres da família.

Envio um pouco de dinheiro. Mas mando todo mês pelo meu pai que faz corrida aqui, rancho, porque aqui as coisas são mais em conta e compro tudo que as minhas filhas precisam. Ajuda a minha mãe e assim ela me ajuda com as meninas. (mulher, 29 anos, natural do Ceará, 5 anos na fronteira Brasil/Venezuela) ${ }^{25}$

Já para os homens o envio do dinheiro/rancho ${ }^{26}$ significa a concretização da condição de pai e provedor do lar.

Envio muito pouco dinheiro. Esse câmbio está muito ruim. Mando mais presentes. O meu filho de quatorze anos queria um telefone, eu fui comprei e mandei. Envio sempre pelo correio, vou até línea e envio. Para minha mãe não pode faltar! Agora depende, agora enviei para ela um cordão de prata cheio de enfeites, próprios para mulher, outra vez enviei um termo guarda café. Eu falo sempre com a minha mãe, agora que sair da mina minha primeira preocupação é falar com a mãe, ela já tem quase 70 anos. Assim, não sou esquecido e nem eles esquecem de mim. Aqui tem gente que parece bicho, quando sai da Mina não tem nem para quem ligar. Eu pelo menos ainda tenho família e demonstro que me importo com eles. (homem, natural do Amazonas, 43 anos, 5 anos na fronteira Brasil/Venezuela) ${ }^{27}$

Entrava em contato com os filhos quando enviava dinheiro para eles, mas a coisa foi ficando difícil na mina e fiquei um tempo sem ligar porque não tinha dinheiro para mandar. Hoje não tenho contato algum com eles. (homem, natural da Bahia, 71 anos, 30 anos na Venezuela) ${ }^{28}$

As remessas agem como extensão da "pessoa" que doa no seio familiar, ou seja, o envio de coisas, dinheiros e informações os mantêm presentes no cotidiano, mesmo quando existe uma distância física. Dito de outra forma, o bem enviado interfere diretamente na dinâmica das relações familiares que concretizam a proximidade da pessoa que doa pelo que é dado. Os parentes são partes do garimpeiro e o garimpeiro faz parte da vida de seus parentes,

\footnotetext{
${ }^{25}$ Ibidem, p. 78.

${ }^{26} \mathrm{O}$ "rancho" é a compra mensal de alimento e itens básicos para subsistência da unidade doméstica.

27 Ibidem, p. 78.

${ }^{28}$ Ibidem, p. 68.
} 
mesmo à distância. Essa condição compósita dialoga com as sugestões de Marilyn Strathern ${ }^{29}$, para quem as pessoas são, constantemente, "construídas como lócus plural e compósito das relações que as produzem".

No caso das mulheres do garimpo, remessas implicam na possibilidade de negociar sobre decisões importantes na vida dos parentes. Do lado feminino, falam sobre a possibilidade de decidir sobre os rumos da família por meio de uma autoridade compartilhada com aquelas que ficaram em casa. A mulher de família no garimpo é aquela que compartilha uma moralidade cristã, desempenhando funções dos cuidados de manutenção da vida em troca de ouro, cozinhando, lavando roupas. Esse status é construído em oposição a outras mulheres que trabalham nas currutelas ${ }^{30}$, que embora também enviem remessas as famílias no Brasil, são percebidas como mulheres sem família.

As remessas, pelo lado masculino, falam do rol de provedor, assumido pelo homem. A capacidade ou não de garantir o sustento da família provoca diretamente a masculinidade dos homens. Pode ser motivo de orgulho ou motivo de baixa autoestima. No caso de instabilidade financeira ou em conjuntura de parcos recursos os homens tendem a diminuir os contatos familiares para evitar constrangimentos. O lugar de provedor nas relações com a mãe, os filhos, as esposas, revela um certo status da pessoa. As remessas para a manutenção das relações com as famílias distantes são indicadores do sucesso e da condição de homem de família, tendo em vista que os contatos mais frequentes com a família fortalecem laços afetivos e emocionais, ao mesmo tempo que demandam maiores obrigações com relação a ela, principalmente suporte financeiro para o sustento. Ter uma casa e pessoas para quem direcionar seus ganhos e seus sonhos de retorno, reforça a própria condição de humanidade separada dos bichos. Quem tem família é gente, no contexto dos garimpeiros brasileiros na Venezuela. Demonstrar laços de filiação e alianças, fazendo parte de uma família, portanto, significa ter alguma origem, ter pessoas que se preocupam com ele e que virão ao seu socorro em casos de emergência.

\section{Parentesco e livre obrigação}

Na realidade das famílias abordadas neste trabalho, é possível verificar a existência de algum princípio de reciprocidade operando como elemento explicativo sobre a continuidade ou descontinuidade dos vínculos afetivos. A família dos alternativos existe enquanto as pessoas cultivam as suas conexões afetivas, por meio do compartilhamento do espaço, da comensalidade, dar

\footnotetext{
${ }^{29}$ STRATHERN, Marilyn. O gênero da dádiva: problemas com as mulheres e problemas com a sociedade na Melanésia, p. 40.

${ }^{30}$ Local de comércio sexual, geralmente situado próximo os centros comercias do garimpo. Trabalho majoritariamente desempenhado por mulheres.
} 
e receber trabalho, etc. Pelo observado em Alto Paraíso, a família ganha vida no intercâmbio de prestações materiais e espirituais. No contexto da mineria, as relações de familiaridade são derivadas da consanguinidade e perpetuadas pelas eventuais remessas que os garimpeiros enviam às suas mães, esposas, irmãos e filhos como cumprimento de suas obrigações de parentesco. Em ambos os casos é possível observar que a continuidade das famílias se dá por meio das obrigações assumidas pelos indivíduos.

Sentir-se fazendo parte de alguma família é assumir obrigações com as outras pessoas que participam deste agrupamento. Sentir-se parte da família é fazer parte da vida de outras pessoas, seja colaborando cotidianamente no projeto alternativo, seja enviando uma parcela de sua sorte no garimpo para a casa distante. Pode-se dizer que as obrigações, livremente assumidas, tanto perpetuam vínculos familiares, quanto fabricam o parentesco. A manutenção do vínculo é promovida pela distribuição e retribuição de prestações das mais diversas naturezas.

O dar, nas realidades alternativa e garimpeira pode ser relacionado à ideia de Mauss, para quem "apresentar uma coisa de si a alguém é apresentar algo de si. [...] Aceitar alguma coisa de alguém é aceitar algo de sua essência espiritual, de sua alma" ${ }^{\prime 31}$. A coisa dada (seja dinheiro, trabalho, presentes) concretiza a presença, a condição de estar dentro da família, tanto no caso do garimpeiro distante de seus parentes, como no caso dos alternativos quando inventam seus novos laços de parentesco.

A natureza da reciprocidade, sob a ótica de Mauss, está nesse compartilhamento de substância e essência. Aquilo que é dado, deve ser recebido (percebido) e, em momento oportuno, retribuído porque pertencente ao outro. Dar, receber e retribuir são "livres obrigações". Condições de participação numa dada malha de relacionamentos, assumidas de pleno acordo pelos participantes, porque legitimadas pelas convenções sociais.

Uma forma específica de reciprocidade, a hospitalidade (que abrange em muitos casos a comensalidade), é uma importante via de produção de novos parentes. A hospitalidade pode ser pensada como uma abertura à alteridade, condicionada por limites da própria concepção de humanidade em questão. Entre os alternativos, dar a casa e receber o trabalho de um irmão que não tem onde ficar e que sabe cozinhar, é uma transação bem comum. Quem dá a casa, não espera necessariamente a contrapartida imediata, mas esta é a condição para se fazer parte da família. Deve-se entrar no circuito de trocas espontaneamente, retribuindo a hospitalidade com algum dom. A família dos alternativos pode ser caracterizada pela rápida incorporação do "estrangeiro" à vida cotidiana. Espera-se que este assuma sua posição de membro da família e

31 MAUSS, op. cit., p. 200. 
não fique a esperar serviços de hospitalidade. A regra explícita e simples é esta: uma pessoa a mais para comer também é uma pessoa a mais para trabalhar; a casa não é um hotel. Os anfitriões oferecem as suas energias quando abrem a casa, mas gostam de receber as vibrações e a energia criativa do visitante. Há uma certa hierarquia dada pela precedência no local. O(a) dono(a) da casa inaugura um circuito de obrigações que constrange o hóspede a retribuir.

No universo dos garimpeiros brasileiros, a coisa dada carrega consigo o vigor e a força do pertencimento a uma família, tornada uma família transnacional pela circulação não somente de pessoas, mas principalmente de coisas e informações. Conexões à distância que precisam ser reforçadas por um fluxo o mais constante possível de presentes e comunicação, sob pena de romper-se. A doação aparece como retribuição pelos trabalhos de manutenção da casa e cuidados com a reprodução da prole por parte de mães (avós), irmãs e esposas. O garimpeiro se sente livre de obrigações com ex-esposas (e os filhos com elas) quando estas constituem novos matrimônios e transitam para a influência de outro homem. Como nas interpretações clássicas de parentesco, temos nas remessas dos garimpeiros a afirmação e valorização da filiação (na relação de "ego" com sua mãe e/ou com seus filhos) e das alianças matrimoniais.

Como nas trocas do tipo "dádiva", para que os vínculos interpessoais sejam continuados é preciso reconhecimento recíproco em relação à contribuição generosa de cada indivíduo ${ }^{32}$. Nos dois contextos aqui observados, a manifestação desse reconhecimento se dá por meio da expressão de gratidão e da retribuição com generosidade. O parentesco alternativo é consolidado por meio da continuidade na cooperação e extinto com sua interrupção. Já o parentesco garimpeiro é fortalecido pela circulação de bens e informações e eliminado com o seu rompimento. A coisa dada, neste caso, é a própria materialização do afeto e do amor à família, seja por meio da oferta direta de trabalho, seja pela oferta daquilo que foi adquirido como fruto desse trabalho.

\section{Considerações finais sobre parentesco e mobilidade}

É possível reconhecer as fronteiras (e vistos) das famílias de garimpeiros e alternativos a partir das distâncias nas relações de reciprocidade (isto não quer dizer distância física). Entre os alternativos há trocas de trabalho por trabalho ou mesmo dinheiro por trabalho, mas sem implicar no distanciamento característico do negócio. Retribui-se com dinheiro o trabalho de um parente quando esta é a melhor maneira de ajudá-lo em seus próprios planos - nega-se o negócio em nome da intimidade. Para os garimpeiros, a família é como um ponto de ancoragem, um conjunto de pessoas para quem os resultados do trabalho são destinados. As remessas de homens e mulheres do garimpo

32 Ibidem. 
afirmam a sua proximidade com o grupo familiar, seu comprometimento com a continuidade daquele grupo, ainda que separados por grandes distâncias. Nega-se o distanciamento em nome da paternidade. Ambos os contextos, caracterizados pela mobilidade, sugerem que a condição de transnacionalidade é experimentada de formas distintas. Para os alternativos essa condição está associada ao cultivo do parentesco com gente de longe que se aproxima. No caso dos garimpeiros é gente de perto que se distancia.

No mito da comunidade alternativa tudo pertence potencialmente à mesma família, não pode haver acumulação e lucro às custas de outras pessoas e do meio ambiente. A família, metaforicamente, pode ser entendida como uma síntese disjuntiva das esferas da filiação e da aliança, como sugere Viveiros de Castro $^{33}$ para o parentesco ameríndio. As portas da casa estão abertas ao estrangeiro em seu devir-parente (ao mesmo tempo ligado por filiação à Mãe Natureza e por aliança pelo trabalho compartilhado). Doa-se com generosidade e se espera, no tempo da dádiva, uma retribuição que há de fomentar a continuidade da relação e consequentemente o devir de vínculos afetivos e de lealdade duradouros. A hospitalidade dos alternativos (principalmente os mais velhos), dentre as formas de reciprocidade presentes em Alto Paraíso, é a grande incorporadora de novos parentes. Idealmente, todos os filhos da mãe natureza são bem-vindos como iguais e, na prática, é a decisão pessoal de assumir um lugar na circulação de obrigações, dando continuidade às relações de reciprocidade, que definem quem é e quem não é parente no contexto dessa família.

Caminhando da hospitalidade à familiaridade, os alternativos recebem o visitante como alguém que já faz parte do grupo, sem excesso de cortesias. Idealmente, o hóspede não deve se submeter a uma hierarquia local, mas contribuir livremente com a interdependência da casa expressando sua individualidade. Ao aproximar os laços de amizade, considerando-os como laços de parentesco, os alternativos tecem uma família que, entre outras coisas, promove a cooperação para sobrevivência daqueles que estão fixos e também fornece abrigo e proteção para aqueles que estão "na estrada". A valorização do "outro", nesse sentido, implica na valorização daquilo que é ofertado; o que implica, por sua vez, na valorização das relações que constituem a família.

Para os garimpeiros, as doações significam a continuidade de uma posição privilegiada na hierarquia familiar. Quem recebe tem a obrigação de considerar a decisão de quem deu. A gratidão, neste caso, significa uma retribuição ao(à) doador(a) por aquilo que foi dado. A substância do sangue é importante elemento de afirmação de filiação e descendência e do compromisso de doar-se à família. No entanto, esse elemento perde centralidade quando a

\footnotetext{
33 Ibidem.
} 
figura paterna eventualmente é substituída por outro homem que não tem essa substância compartilhada. Nesse caso, extingue-se a aliança com a ex-esposa e com os filhos, sugerindo um deslocamento de foco da consanguinidade, revelando também neste contexto o impacto das "relacionalidades" - à medida que as relações de proximidade não são delimitadas apenas pelo parentesco genealogicamente organizado, mas são construídas com base no estabelecimento de laços de afinidade e lealdade duradouras.

O valor da doação para as famílias dos garimpeiros é tão estimado como no caso dos alternativos. As doações (de perto e/ou de longe) criam e mantém laços de parentesco no enfrentamento aos desafios de uma vida de mobilidade. A hospitalidade dos alternativos permite a existência de uma família distribuída globalmente, enquanto que as remessas dos garimpeiros desde a Venezuela alimentam seus laços consanguíneos com as famílias no Brasil. Daí a importância do parentesco para pensarmos mobilidade.

A metáfora da família e as relacionalidades a ela associadas, oferecem um caminho para comparar diferentes redes e processos migratórios. A relação com uma família tem efeito sobre a condição de gente do garimpeiro, pois amplia e/ou fortalece a noção de ser humano no ambiente do garimpo - diferenciada dos bichos que não teriam família. Já para os alternativos é a extensão da noção de quem faz parte da família que amplia a condição de humanidade - não há separação entre humanos e não-humanos. Ambos se constituem como humanos em relação às suas famílias e em relação à mobilidade. Enquanto uns querem se afastar da natureza por meio da afirmação de uma família, expressão da origem diferenciada (um lugar para voltar), outros querem se aproximar da natureza, reivindicando uma origem comum (um lugar para ir).

\section{Bibliografia}

BRYCESON, Deborah; VUORELLA, Ulla. The transnational family: new European frontiers and global networkings. New York: Berg, 2002.

CARSTEN, Janet. Introduction. In CARSTEN, Janet (ed.). Cultures of Relatedness: new approaches to the study of kinship. Edinburgh: CambridgeUniversity Press, 2000, p. 1-36.

CARSTEN, Janet. After Kinship. Cambridge: Cambridge University Press, 2004.

LOBO, Andréa. Tão Longe, Tão Perto: famílias e 'movimentos' na Ilha da Boa Vista de Cabo Verde. Brasília: ABA Publicações, 2002.

MAUSS, Marcel. Ensaio sobre a Dádiva. In MAUSS, Marcel. Antropologia e Sociologia. São Paulo: Cosac Naify (1925) 2003, p. 183-314.

RIBEIRO, Gustavo Lins. A condição da transnacionalidade. In RIBEIRO, Gustavo Lins. Cultura e Política no mundo contemporâneo. Brasília: Editora UnB, 2000, p. 93-129. 
SANTOS, Sandro Almeida. A família transnacional a Nova Era e a globalização do (((amor))) em Alto Paraíso de Goiás, Brasil. Tese de Doutorado em Antropologia Social. Brasília: UnB, 2013.

STRATHERN, Marilyn. Kinship at the core: an anthropology of Elmdon, Essex. Cambridge: Cambridge University Press, 1981.

STRATHERN, Marilyn. O gênero da dádiva: problemas com as mulheres e problemas com a sociedade na Melanésia. Campinas, SP: Editora da Unicamp, 2006.

THOREAU, Henry David. Walden ou a vida nos bosques. Porto Alegre: L\&PM, (1854) 2010.

VASCONCELOS. Iana dos Santos. Articulações familiares transnacionais: Estratégias de cuidado e manutenção familiar na fronteira Brasil/Venezuela. Dissertação de mestrado: UFPE/UFRR, 2013.

VELHO, Gilberto. O estudo do comportamento desviante: a contribuição da antropologia social. In VELHO, Gilberto. Um antropólogo na cidade: ensaios de antropologia urbana. Rio de Janeiro: Zahar, 2013, p. 36-52.

VIVEIROS DE CASTRO, Eduardo. Metafísicas canibais: elementos para uma antropologia pós-estrutural. São Paulo: Cosac Naify, 2015.

Recebido para publicação em 23.12.2016

Aceito para publicação em 07.03.2017

Received for publication in December 23 ${ }^{\text {th }}, 2016$

Accepted for publication in March 07 ${ }^{\text {th }}, 2017$

ISSN impresso 1980-8585

ISSN eletrônico 2237-9843

http://dx.doi.org/10.1590/1980-85852503880004914 